\title{
Atlantooccipital dislocation in children: presentation, diagnosis, and management
}

\author{
Michael P. Steinmetz, M.D., Roseanna M. Lechner, M.D., \\ AND JAMES S. ANDERSON, M.D. \\ Department of Neurosurgery, Cleveland Clinic Foundation; and Division of Neurosurgery, \\ MetroHealth Medical Center, Cleveland, Ohio
}

\begin{abstract}
Atlantooccipital dislocation (AOD) injuries are highly unstable, and usually result in significant neurological injury and death. Recently the postinjury survival period has increased. In a review of the literature the authors found 41 cases in which survival was greater than 48 hours. This is likely due to improved on-scene resuscitation, spinal immobilization, transportation, new diagnostic techniques, and a higher index of suspicion.

Diagnosis is usually made with plain cervical radiographs, but there are shortcomings associated with this modality in the pediatric population. Diagnosis is aided by high-resolution computerized tomography and magnetic resonance imaging. Infants and toddlers may undergo orthotic immobilization alone, whereas older children usually undergo early occipital cervical fusion. Those with incomplete AOD may be managed successfully with orthotic immobilization.
\end{abstract}

\section{KEY WORDS • atlantooccipital dislocation • craniovertebral junction • halo vest • children}

Traumatic AOD is usually a fatal injury and is not as rare as once thought. ${ }^{1,5}$ Patients dying of cervical spine injury (a rate between 19 and 30\%) are found to have AOD at postmortem examination. ${ }^{1,5}$ In a review of the literature we found 41 cases in which survival was greater than 48 hours in children suffering AOD. The majority of these cases were treated in the last decade. . $^{6,9,12,25-27,32,41,43-45,47}$ This is likely due to improved on-scene resuscitation, spinal immobilization, transportation, newer diagnostic techniques, and a higher index of suspicion. ${ }^{27,33,43}$

Atlantooccipital dislocation occurs more frequently in children. This is because of the relatively small occipital condyles, ligamentous laxity, and a flat articulation between the occiput and the atlas. The relatively large head and shorter neck of the young child places the fulcrum of the cervical spine in the occipitoatlantoaxial complex, ${ }^{42}$ which puts this region under great risk for dislocation during a traumatic event. In this review we discuss the anatomy, biomechanics, presentation, diagnostic workup, and management of this entity in children.

\footnotetext{
Abbreviations used in this paper: AOD = atlantooccipital dislocation; $\mathrm{CT}=$ computerized tomography; $\mathrm{CVJ}=$ craniovertebral junction; $\mathrm{MR}=$ magnetic resonance; $\mathrm{VB}=$ vertebral body.
}

\section{ATLANTOOCCIPITAL INJURY IN CHILDREN}

\section{Anatomical Features}

The occipital condyles are paired semilunar projections from the inferior surface of the occiput. ${ }^{2}$ The condyles articulate with the lateral masses of the atlas. These lateral masses slope medially to match the occipital condyles, forming a mediolateral wedge. The condyles are seated in concavities in the lateral masses. These concavities develop with age and are then absent in the pediatric population; this may explain an increased propensity for AOD in this patient group. There is a loose ligamentous capsule surrounding this atlantooccipital articulation.

Ligaments provide most of the stability of the occipitocervical junction. The most important of these ligaments in regards to stability are the tectorial membrane, cruciate ligament, and alar and apical ligaments. The tectorial membrane is the cranial extension of the posterior longitudinal ligament and attaches to the anterior aspect of the foramen magnum. The cruciate ligament consists of the transverse ligament, which attaches to the C-1 lateral masses, and vertical triangular-shaped bands that extend to the foramen magnum. ${ }^{2}$ The paired alar ligaments span from the tip of the dens to the medial aspect of the occipital condyles, whereas the apical ligament attaches the 
tip of the dens to the foramen magnum (Fig. 1). Many of these ligamentous structures are underdeveloped in the child, and there is an inherent increased ligament laxity in this age group. These variables may lead to increased incidence of AOD in infants and young children.

\section{Biomechanical Properties}

The atlantooccipital junction permits $25^{\circ}$ of flexionextension, $5^{\circ}$ of lateral bending, and $5^{\circ}$ of unilateral rotation..$^{3,46}$ Extension is limited by the tectorial membrane, whereas flexion is limited by impaction of the dens and the basion. ${ }^{2}$ Lateral bending and rotation are checked by the alar ligaments. Both the tectorial membrane and the alar ligaments resist distraction. The major stabilizing structures of the occipitocervical junction are the tectorial membrane and the alar ligaments.

\section{Mechanism of Injury}

Although it has been demonstrated that sectioning of the alar ligaments and tectorial membrane allows forward dislocation of the cranium with respect to the spine, more extensive ligamentous injury is usually required before

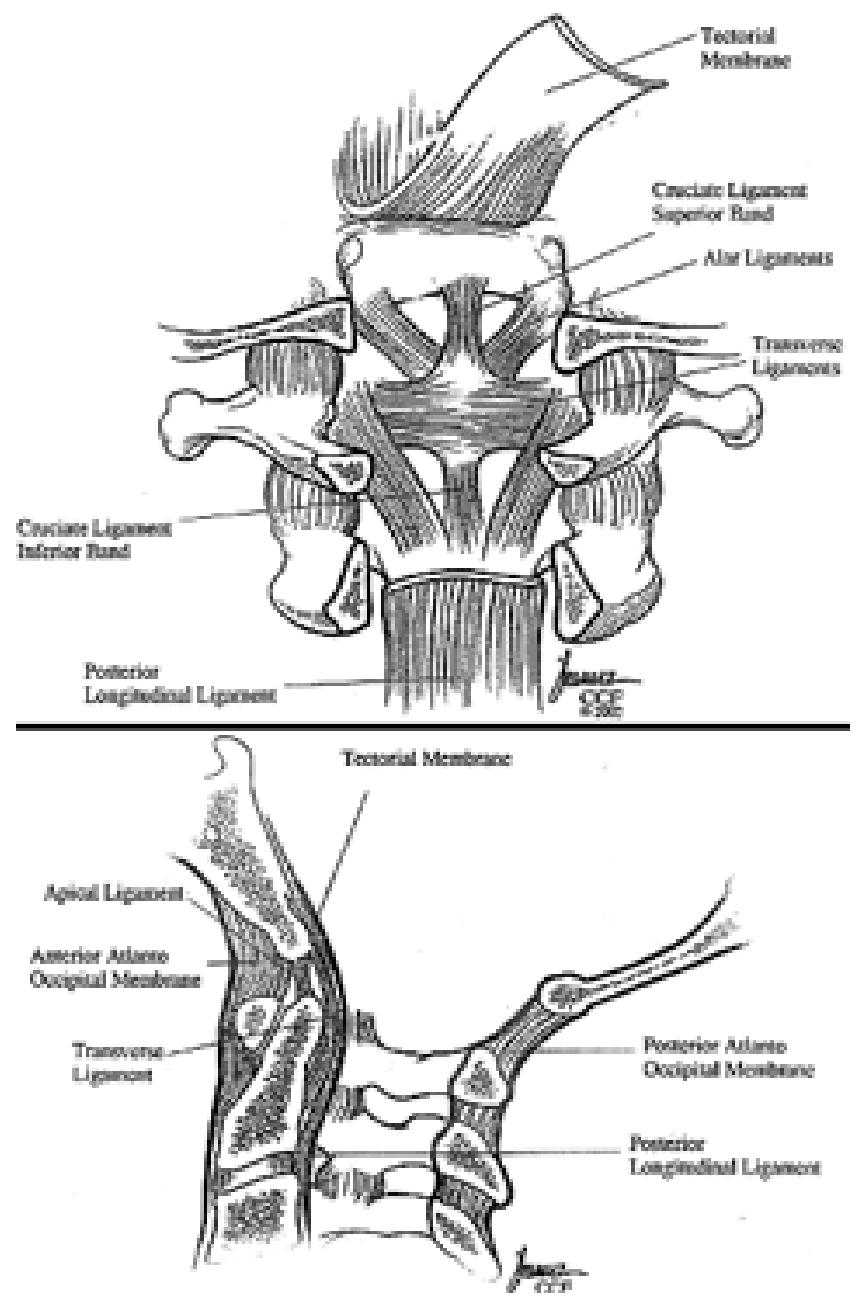

Fig. 1. Ligamentous structures of the CVJ. Upper: Posterior view. Lower: Lateral view.
AOD occurs. Some authors have theorized that extreme hyperflexion leads to rupture of the tectorial membrane and AOD, ${ }^{12,19,31,37}$ whereas others have posited that a component of lateral flexion is also necessary. ${ }^{32,47}$ Currently it is believed that AOD probably occurs as a result of a combination of forces (hyperextension, lateral flexion, and/or hyperflexion).

\section{Patient Presentation}

Patients with AOD often have sustained an associated head injury $9,19,21,22$ and the prominent symptoms of this head injury may conceal that of the cervical spine. ${ }^{23}$ This makes the initial neurological examination difficult. Of note, in one third of the previous reports on postinjury survival, AOD was overlooked at the first examination., ${ }^{9,12}$

Most patients present after intubation and often under cardiovascular inotropic support. Medullary injury may explain this cardiopulmonary instability ${ }^{13,19,32,43}$ and may also indicate the reason for the high mortality rates. Most often there is quadriplegia or quadriparesis due to spinal cord injury. ${ }^{12,14,19,25,31,32,34,47}$ Cranial nerve palsies are also commonly found. Those most often injured are the sixth and the ninth through 12th cranial nerves. ${ }^{6,14,47}$ This is most likely due to stretch injury, although sixth cranial nerve malfunction may be more related to the associated head injury. ${ }^{33}$ The vertebral arteries may also be damaged as a result of dissection, compression, or thrombosis. $12,14,17$, 21,37,47 Despite the significant deficits that may occur, patients may present without neurological deficits. ${ }^{6,13,25}$

As can be seen by the wide range of presentation, one needs a high index of suspicion to make the diagnosis of AOD. Essentially any victim of a motor vehicle accident should be suspected of having sustained an AOD, especially if cardiorespiratory compromise or a significant neurological deficit is present.

\section{Initial Management Including Imaging}

Initial management is directed toward maintaining adequate ventilation and cardiovascular support. The cervical spine should be immobilized in the neutral position. Cervical radiographs should be acquired. Most often the injury is apparent on the initial lateral cervical radiograph (Fig. 2), but in cases in which it is not initially evident, many schemes have been developed. These schemes are applied to the three-view or five-view cervical radiograph series. Examples include the Power ratio and the X-line method. These radiographic methods relate cranial anatomy to spinal anatomy but have their shortcomings in children. The opisthion is not well visualized in children, and there is incomplete ossification of the odontoid.

Computerized tomography scanning is a far more sensitive method for determining the craniocervical relationships. ${ }^{4}$ Fine-cut CT scanning with the addition of coronal and sagittal reconstructions may easily demonstrate translatory or distractive lesions ${ }^{2}$ (Fig. 3 left).

Magnetic resonance imaging has been proposed as a very useful tool to aid diagnosis of AOD in children. It provides superb visualization of the ligaments involved and the supporting soft-tissue structures ${ }^{42}$ (Fig. 3 center). It also identifies spinal cord injury (Fig. 3 right). Disruption of the tectorial membrane is likely the critical threshold for instability of the occipitoatlantoaxial region. ${ }^{42}$ 


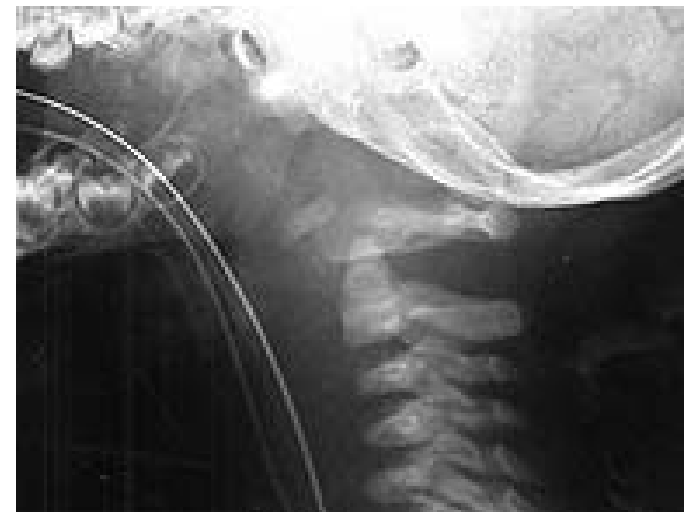

Fig. 2. Lateral cervical radiograph clearly demonstrating AOD.

Therefore disruption of this ligament, as demonstrated on MR imaging, would be diagnostic of complete AOD. Lesser degrees of injury at the craniovertebral junction, such as partial ligamentous injury, are also revealed on MR imaging. Thus, this modality would also allow the diagnosis of incomplete AOD.

A new ratio has been proposed to aid in the evaluation of tectorial membrane disruption and thus complete AOD. This technique measures the ratio of the interspinous distance between $\mathrm{C} 1-2$ and $\mathrm{C} 2-3$ on the lateral cervical radiograph. The shortest distance between the inferior cortex of the C-1 posterior ring to the superior cortex of the $\mathrm{C}-2$ spinous process is divided by the shortest distance between the inferior cortex of the $\mathrm{C}-2$ spinous process to the superior cortex of the $\mathrm{C}-3$ spinous process. ${ }^{42} \mathrm{~A} \mathrm{C} 1-2 /$ C2-3 ratio greater than 2.5 has an $86 \%$ sensitivity and $100 \%$ specificity for tectorial membrane disruption ${ }^{42}$ and hence AOD.

\section{Classification of Atlantooccipital Dislocation}

Atlantooccipital dislocation has been divided into three specific types. ${ }^{43}$ Type I involves anterior displacement of the occiput with respect to the atlas; Type II is primarily a longitudinal distraction with separation of the occiput from the atlas; and Type III denotes posterior displacement of the occiput on the atlas (Fig. 4).

\section{Management of Dislocation}

The effort of cervical traction is unclear. Some authors have argued that it should be used, ${ }^{12-14,16,19,31,34,37,47}$ whereas others believe that it is not necessary. ${ }^{25,32}$ There is no clear evidence that traction has led to decreased function. ${ }^{43}$ In those who have suffered a Type II injury, traction would not be indicated because good alignment is already present with longitudinal distraction. Patients who have sustained Type I and Type III injuries, however, may benefit from cervical traction, which may realign the spine and decompress the brainstem and spinal cord. In some cases in which cervical traction has been applied, neurological deficits have resolved. ${ }^{13,14,31}$

The authors believe that early halo vest immobilization should be instituted for reduction of the dislocation. Farley, et al., ${ }^{15}$ and Evarts ${ }^{14}$ have also advocated early halo immobilization. In children younger than 6 years of age, multiple pins should be applied to increase the distribution of the force along the child's skull, and they should be placed only finger tight. Frequent radiographs should be obtained to ensure adequate reduction. Lateral cervical radiographs should be acquired once a day until there is evidence of maintained reduction, after which they should be obtained every 3 days or once a week. In very small children continued deformity reduction may be difficult because the vest may fit poorly. We devised a strap system for the vest to prevent it from "riding up;" by this method reduction is maintained. ${ }^{41}$

The definitive management of this injury in children is unclear. Most authors have advocated early posterior

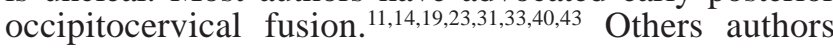
have initially attempted nonoperative orthotic immobilization, but because of persistent instability fusion was per-

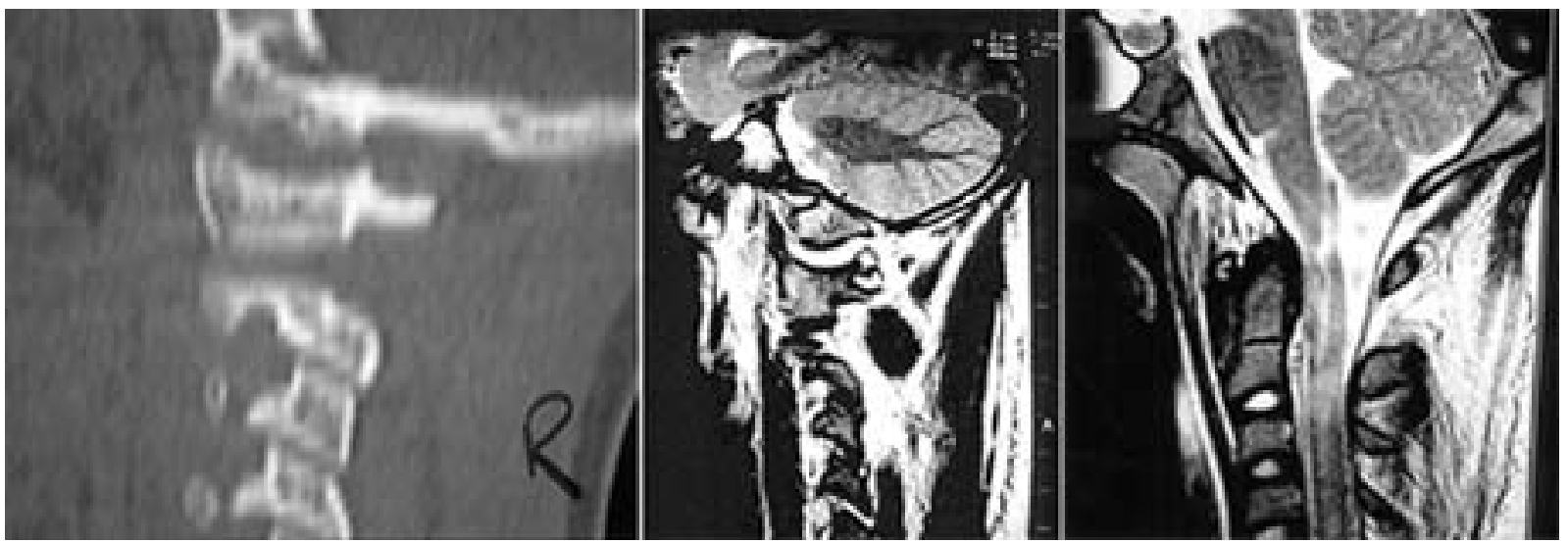

Fig. 3. Left: Sagittal CT reconstruction of the cervical spine obtained in a child with AOD. There is longitudinal displacement of the occipital condyle with respect to the C-1 lateral mass. Center: Sagittal $\mathrm{T}_{2}$-weighted MR image of the cervical spine obtained in a child with AOD. There is increased intensity in the right atlantooccipital joint space, with separation of the occipital condyle and C-1 lateral mass. Right: Sagittal $\mathrm{T}_{2}$-weighted MR image obtained in a 13-yearold patient with AOD. There is increased intensity in the region of the tectorial membrane and alar ligaments. There is separation of the clivus with respect to the dens. Significant injury to the spinal cord can also be seen. 


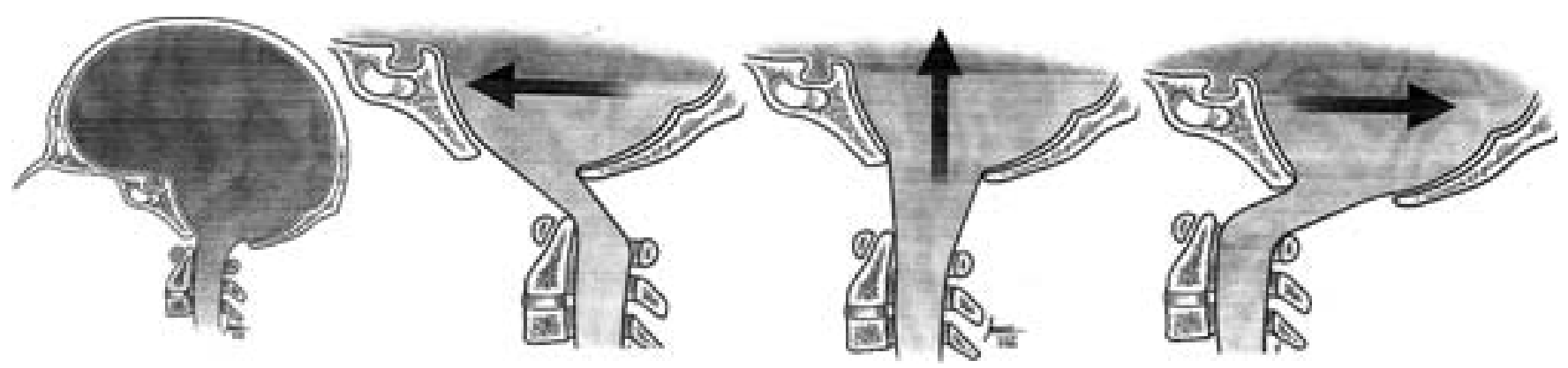

Fig. 4. Diagrams depicting the classification scheme of AOD. Type I involves anterior displacement of the occiput with respect to the atlas. Type II involves longitudinal distraction. Type III involves posterior displacement of the occiput with respect to the atlas.

formed. ${ }^{20,31}$ Because ligaments in the child are growing and undergoing considerable remodeling, the capacity for repair is greater in the musculoskeletally immature child than in the adult..$^{30}$ This leads us to believe that this injury in the musculoskeletally immature child is capable of healing without internal fixation and fusion. There have been reports in the literature that AOD in children has healed after orthotic immobilization alone..$^{15,29,35,47}$ The authors have previously reported on two children with AOD who were successfully treated with orthotic immobilization alone. ${ }^{41}$

Several factors should be considered when deciding if a surgical or nonsurgical strategy will be used. Considerations should be given to the patient's age, type of AOD (complete or incomplete), and neurological injury status.

The patient's age should have considerable influence on the decision making. Infants and toddlers have a different bone composition compared with older children, and they also have a higher propensity to heal a ligamentous injury. At these ages the bone is almost cartilaginous, which makes surgical intervention somewhat more difficult. Ossification of C-1 is not complete until 4 to 5 years of age, and the subaxial cervical spine has not completed ossification until 2 to 4 years of age. ${ }^{30}$ Because autograft could not be used (donor site availability), allograft would be necessary. Surgical fixation and fusion in this age group would prove to be difficult, making a nonsurgical approach more appealing. In our experience, AOD in patients younger than 3 years of age may heal without fixation, but it is unclear at what age this healing potential ends. Georgopoulos, et al., ${ }^{20}$ reported on two cases (a 5and a 6-year old patient, respectively), both with AOD, in whom conservative therapy failed, thus required occipitocervical fixation. In contrast, Farley, et al. ${ }^{15}$ reported on a 7 -year-old child in whom AOD healed with halo immobilization alone. Perhaps those children between 4 and 7 years of age represent a "gray" zone for definite ability to heal without surgery.

With the wider usage of MR imaging, the diagnosis of complete (total tectorial membrane disruption) and incomplete (incomplete rupture of the tectorial membrane and alar ligaments or disruption of other ligaments) AOD has been possible. Once the diagnosis of AOD has been established, a distinction between complete and incomplete AOD should be determined. This is based on MR imaging finds and/or $\mathrm{C} 1-2 / \mathrm{C} 2-3$ ratio. Classification of complete, incomplete or no neurological injury should also be made.

Incomplete AOD, regardless of whether neurological injury is present, should be treated with orthotic immobilization. By virtue of their being only partial injuries to ligamentous structures, they are more stable. These types of injuries have been reported to heal with excellent results without surgery. ${ }^{22,42}$ The choice of orthosis is surgeon dependent. Options include halo or cervicothoracic orthosis. Sun, et al. ${ }^{42}$ reported a series of six partial AOD in which five healed in orthoses alone, and one was lost to follow up. In those children older than 3 years of age with a complete AOD, early occipital cervical fusion is required.

\section{Surgical Treatment}

The surgical management of AOD requires occipital cervical fusion. We prefer that the patient, immobilized in a halo vest, be brought to the operating room with the AOD already in a reduced position. Awake intubation should be performed using fiberoptic assistance. Next the patient should be positioned prone while awake, and reexamined before anesthesia is induced. If possible, the posterior halo vest is left in place during surgery, but it may be removed if warranted.

\section{Wire and Bone Graft}

Early techniques consisted of the use of bone grafts and wire or cable. The occiput may be secured to either $\mathrm{C}-1$ or the $\mathrm{C} 1-2$ complex directly with wire or cable, or indirectly via the occipitocervical placement of bone grafts. These bone grafts are then secured to the occipitocervical complex by using wire. These techniques do not provide immediate stability and often require postoperative halo immobilization. At times, reduction of the dislocation may be difficult to maintain by the aforementioned technique and the incidence of pseudarthrosis may be unacceptable.

\section{Contoured Loop Fixation}

Probably the most popular instrumentation strategy, and a more modern one, is the placement of a contoured loop that, using multistranded cable or wire, is secured to the occiput and upper cervical spine. A standard midline exposure of the suboccipital bone and upper cervical spine is performed. A precontoured loop or rectangle is placed 
into the exposed CVJ to ensure adequate fit. The loop may be further contoured if needed. Burr holes are marked on the suboccipital bone on either side of the rod. Thus, four burr holes are created. Next, the dura mater is carefully stripped between the burr holes on either side of the midline and a double cable is passed from burr hole to burr hole. This provides two cables on either side of midline with which to secure the loop to the suboccipital bone. In very young children, the use of four burr holes may not leave enough bone to ensure adequate fixation of the implant, and thus a burr hole may be placed on either side of midline and the cable passed around the lip of the foramen magnum to secure the implant.

A double cable is then passed under the posterior arch of $\mathrm{C}-1$ and repeated beneath the lamina of C-2 and/or $\mathrm{C}-3$. When these cables are separated, there is one cable for each side. The ligamentum flavum is stripped using small curettes prior to the passage of the cables. Care must be taken when placing the sublaminar cables. Constant tension must be placed on the cable so the most anterior part, which loops around the lamina, does not impinge on the spinal cord and cause injury.

After the cables or wire are in place, the contoured loop is inserted into the CVJ. The cables are then sequentially tightened. Care should be taken not to overtighten the cables, which might encourage the wire or cable to cut through the native bone and lead to construct failure.

A bicortical iliac crest bone graft is harvested. The graft is placed in an onlay manner between the arms of the loop onto the decorticated suboccipital and upper cervical bone. The graft may be held in place by a loop of wire between the arms of the implant.

Postoperatively patients may wear a rigid cervical collar or undergo halo immobilization therapy depending on the surgeon's preference.

Nakagawa, et al., ${ }^{28}$ reported a similar technique as the aforementioned. During a 5-year period, eight children (mean age 8.3 years) underwent occipitocervical fusion in which a contoured rectangle and sublaminar wire were placed for fixation. A solid fusion was attained in all patients, and additionally no loss of correction occurred with surgery. During a mean follow-up period of 5.9 years, abnormal curvature of the spine was absent in all patients. The rate of increase in the height of the C-2 VB compared with those below C-3 was significantly less; however, the rate of increase in the width of the VB as well as the anteroposterior diameter of the spinal canal of the C-2 VB and below C-3 did not differ significantly.

\section{Atlantoaxial Transarticular Screw Placement}

Because the aforementioned craniovertebral fusion strategies are often associated with a relatively high fusion failure rate, ${ }^{10,18,36,38,39}$ rigid screw fixation has been advocated. A technique described by Brockmeyer and Apfelbaum $^{7}$ involves a contoured loop fixation with screws into the suboccipital bone as well as C-1 and C-2 (that is, transarticular fixation). This procedure provides rigid immobilization of the occipitocervical region and allows immediate patient mobilization. Furthermore, the need for halo immobilization is avoided.

In this strategy the first step is deciding if the patient is an appropriate candidate for screw fixation. Among the aforementioned standard neuroimaging modalities, patients should undergo thin-slice CT scanning of the CVJ (occiput-C3). The data may be transferred to a workstation capable of multiplanar reconstruction. Three-dimensional reconstruction of thin-slice CT scans allows the surgeon to view the patient's individual osseous anatomy and its suitability for transarticular screw fixation. The screw trajectory is visualized on 3D multiplanar images. The trajectory pathway should be able to accommodate at least a 3.5-mm transarticular screw and avoid potential damage to neurovascular structures (for example, the vertebral artery). Many modern workstations allow the surgeon to "pass" a virtual transarticular screw and thus assess the feasibility of the procedure. In conducting a similar technique, Brockmeyer, et al. ${ }^{8}$ found that in $94 \%$ of pediatric patients at least one $\mathrm{C} 1-2$ joint was considered anatomically suitable for C1-2 transarticular screw placement.

After the anatomy has been determined suitable for at least one transarticular screw, the CVJ is approached in a standard fashion, and the suboccipital bone and the C1-3 region are exposed. Either 3.5- or 4-mm transarticular screws are placed. A preformed U-shaped implant (OMI Surgical Products, Cincinnati, $\mathrm{OH}$ ) is then placed into the wound and secured to the occiput by using three screws ranging in length from 6 to $18 \mathrm{~mm}$ (the longest screws are placed into the midline keel). The transarticular screws are then connected to the implant by using special couplers. Finally, a bicortical iliac crest graft is placed between the arms of the contoured implant onto the decorticated occiput-C2 complex. The bone graft may be held in place by a cable looped around the graft and implant. As previously noted, in some patients a transarticular screw is placed only unilaterally. In this case, a multistranded cable may be placed around the C-1 lamina on the side that was unable to accommodate the transarticular screw to secure the implant. The technique may be modified to adapt to various occipitocervical constructs (for example, Yshaped implants).

Brockmeyer and Apfelbaum ${ }^{7}$ performed the aforementioned technique in 10 pediatric patients (age range 4-16 years). They reported a $100 \%$ fusion rate within 4 months of surgery. There were no cases of vascular injury. In one patient, two of the three occipital screws backed out. At reoperation, a solid osseous fusion was demonstrated and the screws were not replaced.

Most surgeons agree that occipitocervical screw fixation is superior to sublaminar cable (or wire) fixation. ${ }^{24}$ Its efficacy in children, however, particularly regarding the $\mathrm{C} 1-2$ region, is unclear. Brockmeyer and Apfelbaum 7 have stated that the procedure can consistently be performed in children as young as 4 years of age. They described a 3-year-old patient who successfully underwent the procedure. Questions have been raised about future spinal maturation potential and end-fusion degeneration after placement of rigid screw instrumentation in the pediatric cervical spine. Because a child's craniovertebral region reaches an adult size and configuration by approximately age 8 to 10 years, the potential for significant growth limitation is minimal. ${ }^{7}$ Brockmeyer and Apfelbaum have not found any limitations to growth potential or development of juxtafusion disease in their series, although they have acknowledged that their follow-up period is relatively short. 
Perhaps in the future absorbable implants will be appropriate for occipitocervical fusion in the young. Optimally, they would provide immediate rigidity until fusion has occurred and then be resorbed, thereby not affecting any future growth potential.

\section{Orthotic Management}

The exact length of time a halo vest or other orthosis is required to allow adequate healing is uncertain. In six cases of incomplete AOD reported by Sun, et al. ${ }^{42}$ one wore a collar for 2 weeks, and the other five were treated with a cervicothoracic orthosis for 8 weeks. Healing occurred in all patients. In reports by Farley, et al., ${ }^{15}$ and Naso, et al. ${ }^{29}$ the patients were treated with a halo immobilization for 3 months. In our cases we prescribed halo vests for 10 weeks, followed by a Minerva-like orthosis for 4 weeks, and finally cervical collars for an additional 4 weeks. Dynamic radiographs are obtained at each change to verify stability. This protocol minimized opportunities for halo vest-related complications, yet still provided an additional 4 weeks of occipitocervical stability.

\section{CONCLUSIONS}

Atlantooccipital dislocation is probably more common than realized, especially in the pediatric population. A high index of suspicion is required to make the diagnosis. Radiographic diagnosis is usually obvious on the initial lateral cervical radiograph, but there are limitations in children. Magnetic resonance imaging and the use of the $\mathrm{C} 1-2 / \mathrm{C} 2-3$ ratio are helpful in cases in which findings are equivocal. Initial management involves airway protection and cervical immobilization. Infants and toddlers may be treated nonsurgically by close observation. Those with incomplete ligamentous injury (incomplete AOD) may also be treated with orthosis alone. Older children with complete AOD should usually undergo early occipitocervical fusion.

\section{References}

1. Alker GJ Jr, Oh YS, Leslie EV: High cervical spine and craniocervical junction injuries in fatal traffic accidents: a radiological study. Orthop Clin North Am 9:1003-1010, 1978

2. Anderson PA: Injuries to the occipital cervical articulation, in Clark CR, Ducker TB, Dvorak J (eds): The Cervical Spine, ed 3. Philadelphia: Lippincott-Raven, 1998, pp 387-399

3. Anderson PA: Occipital cervical instability associated with traumatic tears of the transverse ligament of the atlas. Orthop Trans 12:41, 1988 (Abstract)

4. Anderson PA, Montesano PX: Traumatic injuries of the occipital-cervical articulation, in Camins MB, Oleary PF (eds): Disorders of the Cervical Spine. Baltimore: Williams and Wilkins, 1992, pp 273-284

5. Bohlman HH: Acute fractures and dislocations of the cervical spine. An analysis of three hundred hospitalized patients and review of the literature. J Bone Joint Surg Am 61:1119-1142, 1979

6. Bools JC, Rose BS: Traumatic atlantooccipital dislocation: two cases with survival. AJNR Am J Neuroradiol 7:901-904, 1986

7. Brockmeyer DL, Apfelbaum RI: A new occipitocervical fusion construct in pediatric patients with occipitocervical instability. Technical note. J Neurosurg (Spine 2) 90:271-275, 1999
8. Brockmeyer DL, York JE, Apfelbaum RI: Anatomical suitability of C1-2 transarticular screw placement in pediatric patients. J Neurosurg (Spine 1) 92:7-11, 2000

9. Collalto PM, DeMuth WW, Schwentker EP, et al: Traumatic atlanto-occiptial dislocation. Case report. J Bone Joint Surg Am 68:1106-1109, 1986

10. Coyne TJ, Fehlings MG, Wallace M, et al: C1-C2 posterior cervical fusion: long-term evaluation of results and efficacy. Neurosurgery 37:688-693, 1995

11. Donahue DJ, Muhlbauer MS, Kaufman RA, et al: Childhood survival of atlantooccipital dislocation: underdiagnosis, recognition, treatment, and review of the literature. Pediatr Neurosurg 21:105-111, 1994

12. Dublin AB, Marks WM, Weinstock D, et al: Traumatic dislocation of the atlanto-occipital articulation (AOA) with shortterm survival. With a radiographic method of measuring the AOA. J Neurosurg 52:541-546, 1980

13. Eismont FJ, Bohlman HH: Posterior atlanto-occipital dislocation with fractures of the atlas and odontoid process. J Bone Joint Surg Am 60:397-399, 1978

14. Evarts CM: Traumatic occipito-atlanto dislocation. J Bone Joint Surg Am 52:1653-1660 1970

15. Farley FA, Graziano GP, Hensinger RN: Traumatic atlantooccipital dislocation in a child. Spine 17:1539-1541, 1992

16. Farthing JW: Atlantocranial dislocation with survival. A case report. NC Med J 9:34-36, 1948

17. Finney HL, Roberts TS: Atlantooccipital instability. Case report. J Neurosurg 48:636-638, 1978

18. Fried L: Atlanto-axial fracture dislocation. Failure of posterior C1 to C2 fusion. J Bone Joint Surg Br 55:490-496, 1973

19. Fruin AH, Pirotte TP: Traumatic altlantooccipital dislocation. Case report. J Neurosurg 46:663-666, 1977

20. Georgopoulos G, Pizzutillo PD, Lee MS: Occipito-atlantal instability in children. J Bone Joint Surg Am 69:429-436, 1987

21. Gerlock AJ Jr, Mirfakhraee M, Benzel EC: Computed tomography of traumatic atlantoocciptial dislocation. Neurosurgery 13:316-319, 1983

22. Grabb BC, Frye TA, Hedlund GL, et al: MRI diagnosis of suspected atlanto-occipital dissociation in childhood. Pediatr Radiol 29:275-281, 1999

23. Hosono N, Yonenobu K, Kawagoe K, et al: Traumatic anterior altanto-occipital dislocation. A case report with survival. Spine 18:786-790, 1993

24. Hurlbert RJ, Crawford NR, Choi WG, et al: A biomechanical evaluation of occipitocervical instrumentation: screw compared with wire fixation. J Neurosurg (Spine 1) 90:84-90, 1999

25. Kaufman RA, Dunbar JS, Botsford JA, et al: Traumatic longitudinal atlanto-occipital distraction injuries in children. AJNR Am J Neuroradiol 3:415-419, 1982

26. Lee C, Woodring JH, Goldstein SJ, et al: Evaluation of traumatic atlantooccipital dislocations. AJNR Am J Neuroradiol 8:19-26, 1987

27. Levine AM, Edwards CC: Traumatic lesions of the occipitoatlantoaxial complex. Clin Orthop 239:53-68, 1989

28. Nakagawa T, Yone K, Sakou T, et al: Occipitocervial fusion with C1 laminectomy in children. Spine 22:1209-1214, 1997

29. Naso WB, Cure J, Cuddy BG: Retropharyngeal pseudomeningocele after atlanto-occipital dislocation: report of two cases. Neurosurgery 40:1288-1291, 1997

30. Ogden JA: Skeletal Injury in the Child, ed 3. New York: Spinger-Verlag, 2000, pp 708-789

31. Page CP, Story JL, Wissinger JP, et al: Traumatic atlantooccipital dislocation. Case report. J Neurosurg 39:394-397, 1973

32. Pang D, Wilberger JE Jr: Traumatic atlanto-occipital dislocation with survival: case report and review. Neurosurgery 7: 503-508, 1980

33. Papadopoulos SM, Dickman CA, Sonntag VKH, et al: Traumatic atlantooccipital dislocation with survival. Neurosurgery 28:574-579, 1991 
34. Powers B, Miller MD, Kramer RS, et al: Traumatic anterior atlanto-occipital dislocation. Neurosurgery 4:12-17, 1979

35. Putnam WE, Stratton FT, Rohr FR, et al: Traumatic atlanto-occipital dislocations: value of the Powers ratio in diagnosis. J Am Osteopath Assoc 86:798-804, 1986

36. Rockswold GL, Bergman TA, Ford SE: Halo immobilization and surgical fusion: relative indications and effectiveness in the treatment of 140 cervical spine injuries. J Trauma 30: 893-898, 1990

37. Rocksworth GL, Seljeskog EL: Traumatic atlantocranial dislocation with survival. Minn Med 62:151-152, 1979

38. Smith MD, Phillips WA, Hensinger RN: Complications of fusion to the upper cervical spine. Spine 16:702-705, 1991

39. Smith MD, Phillips WA, Hensinger RN: Fusion of the upper cervical spine in children and adolescents. An analysis of 17 patients. Spine 16:695-701, 1991

40. Sponseller PD, Cass JR: Atlanto-occiptial fusion for dislocation in children with neurologic preservation. A case report. Spine 22:344-347, 1997

41. Steinmetz MP, Verrees M, Anderson JS, et al: Dual-strap augmentation of a halo orthosis in the treatment of atlantooccipital dislocation in infants and young children. Technical note. J Neurosurg (Spine 3) 96:346-349, 2002
42. Sun PP, Poffenbarger GJ, Durham S, et al: Spectrum of occipitoatlantoaxial injury in young children. J Neurosurg (Spine 1) 93:28-39, 2000

43. Traynelis VC, Marano GD, Dunker RO, et al: Traumatic atlanto-occipital dislocation. Case report. J Neurosurg 65: 863-870, 1986

44. Van Den Bout AH, Dommisse GF: Traumatic atlantooccipital dislocation. Spine 11:174-176, 1986

45. Watridge CB, Orrison WW, Arnold H, et al: Lateral atlantooccipital dislocation: case report. Neurosurgery 17:345-347, 1985

46. White AA, Panjabi MM: Clinical Biomechanics of the Spine, ed 2. Philadelphia: JB Lippincott, 1990, pp 92-97

47. Woodring JH, Selke AC Jr, Duff DE. Traumatic atlantooccipital dislocation with survival. AJR Am J Roentgenol 137: 21-24, 1981

Manuscript received November 21, 2002.

Accepted in final form January 10, 2003.

Address reprint requests to: Michael P. Steinmetz, M.D., Department of Neurosurgery S-80, Cleveland Clinic Foundation, 9500 Euclid Avenue, Cleveland, Ohio 44195. email: steinmm@ccf.org. 